http://dx.doi.org/10.1590/1678-4162-9299

Arq. Bras. Med. Vet. Zootec., v.69, n.5, p.1191-1197, 2017

\title{
Hematimetria manual e automática em jaguatiricas (Leopardus pardalis - Linnaeus, 1758)
}

\author{
[Manual and automated blood cells count in ocelots \\ (Leopardus pardalis - Linnaeus, 1758)] \\ T.D.P. Silva ${ }^{1}$, L.A. Lacerda ${ }^{2}$, L.S. Carvalho ${ }^{1}$, S.N. Souza ${ }^{1}$, E. Arnhold ${ }^{1}$, \\ F.J.F. Sant'Ana ${ }^{3 *}$, M.C.S. Fioravanti ${ }^{1}$ \\ ${ }^{1}$ Universidade Federal de Goiás - UFG - Goiânia, GO \\ ${ }^{2}$ Universidade Federal do Rio Grande do Sul - UFRGS - Porto Alegre, RS \\ ${ }^{3}$ Universidade de Brasília - UnB - Brasília, DF
}

\begin{abstract}
RESUMO
Aparelhos de automação, cujo uso está estabelecido na hematologia dos animais domésticos, ainda não são empregados rotineiramente em felídeos selvagens. Esse estudo objetivou avaliar a técnica automatizada na contagem de células sanguíneas de jaguatiricas (Leopardus pardalis), comparando-a com a técnica manual. Foram coletadas amostras sanguíneas de oito jaguatiricas, que se submeteram à contagem de eritrócitos, leucócitos, plaquetas e à determinação do volume globular pelo método manual padrão e por meio do aparelho $\mathrm{BC}-2800 \mathrm{VET}^{\circledR}$ com a configuração para gatos domésticos. Os resultados foram avaliados por meio do teste $\mathrm{t}$ para dados pareados, e as técnicas submetidas à análise de correlação de Pearson. A técnica automatizada demonstrou resultados estatisticamente semelhantes para eritrócitos e leucócitos. Apenas para volume globular houve diferença significativa entre as técnicas manual e automatizada, mas a correlação foi alta. Apesar de não haver diferença significativa entre as técnicas para plaquetas, a correlação foi baixa. Conclui-se que o aparelho BC $-2800 \mathrm{VET}^{\circledR} \mathrm{com}^{\mathrm{a}}$ configuração para gatos domésticos é uma técnica confiável na realização do eritrograma e do leucograma para jaguatiricas. Para a determinação do parâmetro volume globular, o aparelho pode ser utilizado, desde que se faça a correção. Para a contagem de plaquetas, a técnica manual é recomendada.
\end{abstract}

Palavras-chave: eritrócitos, hematologia, felidae, leucócitos, hematócrito

\begin{abstract}
Automated equipment, whose use is established in hematology of domestic animals, is not yet routinely used in blood cells count of wildlife, due to lack of studies that validate its use. The purpose of this study was to evaluate the automated technique for blood cells count of ocelots (Leopardus pardalis), comparing it with the manual technique. Blood samples were collected from eight ocelots, which were submitted to counting of erythrocytes, leukocytes, platelets and packed cell volume by the standard manual method and by the device VET ® 2800 BC with the configuration for domestic cats. The results were evaluated using the t test for paired data and the techniques submitted to Pearson correlation. The automated technique showed statistically similar results to erythrocytes and leukocytes. Significant difference was found only for packed cell volume between the manual and automated techniques, but the correlation was high. Although there was no significant difference between the techniques for platelets, the correlation was low. We concluded that the 2800 BC VET ® device with the configuration for domestic cats is a reliable technique in performing the erythrocyte and leukocyte counts for ocelots. The device may be used to determine packed cell volume, provided the correction is made. The manual technique is recommended for the platelet count.
\end{abstract}

Keywords: erythrocytes, hematology, felidae, leukocytes, packed cell volume

Recebido em 7 de novembro de 2016

Aceito em 3 de dezembro de 2016

*Autor para correspondência (corresponding author)

E-mail: santanafjf@yahoo.com 


\section{INTRODUÇÃO}

As jaguatiricas (Leopardus pardalis - Linnaeus, 1758) são felídeos selvagens de porte médio, que pesam entre 11,3 e $15,8 \mathrm{~kg}$ e apresentam coloração amarelada com numerosas manchas negras arredondadas pelo corpo, formando anéis envolvendo a cauda. Esses animais ocorrem em uma ampla variedade de habitats, de florestas tropicais a regiões mais secas, desde que estes apresentem ampla vegetação (Nowak, 1999). Encontram-se listados no apêndice I da CITES (Convention..., 2013) e em situação vulnerável, de acordo com a lista de espécies brasileiras ameaçadas de extinção (Brasil, 2003).

Apesar de se tratar de uma espécie vulnerável, ainda é grande o número desses animais em zoológicos e em áreas de preservação, e alguns estudos têm sido desenvolvidos para o conhecimento dos seus hábitos alimentares (Abreu et al., 2008), ocorrência de doenças (Ullmann et al., 2010) e aspectos reprodutivos (Paz et al., 2010; Silva et al., 2010). A avaliação de características clínicas e laboratoriais também é importante para essa espécie, pois tanto indivíduos criados livremente quanto aqueles criados em zoológicos podem necessitar de acompanhamento e cuidados veterinários, por exemplo, após atropelamentos em rodovias.

Os parâmetros hematológicos atuam como boa ferramenta de investigação clínico-patológica. A interpretação correta desses exames implica o conhecimento e a utilização de valores de referência específicos para a espécie animal, adaptados às condições geográficas, de manejo, de alimentação e até mesmo do próprio laboratório que realizou as análises (González et al., 2001), entretanto existem poucos estudos na literatura sobre os valores hematológicos de pequenos felinos selvagens neotropicais. A necessidade de obtenção de resultados laboratoriais mediante pequenos volumes de amostras, em menor tempo e com menor custo, tem estimulado os laboratórios veterinários a adotar aparelhos hematológicos automatizados (Vieira et al., 2008). Para os gatos domésticos, estudos foram realizados no sentido de comparar a técnica manual com a automatizada para os parâmetros volume globular (Vieira et al., 2008) e contagem de plaquetas (Schweirgert et al., 2010). Também foram comparados aparelhos eletrônicos com diferentes tecnologias em amostras sanguíneas de cães e gatos (Becker et al., 2008). No entanto, são escassos os estudos aplicando essa tecnologia na contagem de células sanguíneas de animais selvagens. Não há, nos aparelhos de automação, configurações ou cartões apropriados e não foram encontrados trabalhos que validem as configurações (softwares) e cartões existentes de animais domésticos para animais selvagens de grupos similares.

O presente estudo objetivou determinar e comparar dados hematimétricos (número de eritrócitos, de leucócitos, de plaquetas e determinação do volume globular) de jaguatiricas (L. pardalis), por duas técnicas de contagem (manual e automatizada).

\section{MATERIAL E MÉTODOS}

O experimento foi previamente aprovado pelo Comitê de Ética e Pesquisa da Universidade Federal de Goiás, com protocolo número 265/2010, e pelo Sistema de Autorização e Informação em Biodiversidade - Sisbio, do Ministério do Meio Ambiente, sob o código de autenticação número 58723968.

Foram utilizadas oito jaguatiricas pertencentes ao Parque Zoológico de Goiânia. Previamente à coleta das amostras, os felídeos foram contidos quimicamente com cetamina (Agener União Saúde Animal, Pouso Alegre, MG, Brasil) e midazolam (Eurofarma, São Paulo, SP, Brasil), nas doses de $10 \mathrm{mg} / \mathrm{kg}$ e $0,2 \mathrm{mg} / \mathrm{kg}$, respectivamente.

As amostras de sangue foram obtidas por meio de punção venosa jugular, utilizando-se tubos de coleta a vácuo de 5,0mL (Becton Dickinson, São Paulo, SP, Brasil) e agulhas calibre 25/8. Foram coletados entre 3,0 e $4,0 \mathrm{~mL}$ de sangue de cada animal em tubo contendo EDTA $K_{3}$ para realização do hemograma. Os tubos foram mantidos em temperatura igual a $4^{\circ} \mathrm{C}$ até a realização dos exames, que foi realizada até seis horas após a coleta.

As contagens pelo método manual de eritrócitos e leucócitos foram realizadas em câmara de Neubauer (Weiser, 2012). A contagem manual de plaquetas foi realizada na lâmina do esfregaço sanguíneo. Na contagem manual, o número de plaquetas foi determinado de forma indireta (Brahimi et al., 2009) pelo método de Fônio, em 
que as plaquetas foram contadas entre 1000 eritrócitos e o número obtido foi multiplicado pelo valor total de eritrócitos $\left(\times 10^{6} / \mu \mathrm{L}\right)$, obtendose o valor de plaquetas em $\left(\times 10^{3} / \mu \mathrm{L}\right)$. Para corar os esfregaços sanguíneos, utilizou-se o corante Leishman (Doles, Goiânia, GO, Brasil). A determinação manual do volume globular (VG) foi realizada pelo método de Strumia, utilizandose tubo capilar de $1,0 \mathrm{~mm}$ de diâmetro interno sem anticoagulante (Perfecta, São Paulo, SP, Brasil) e centrífuga de micro-hematócrito (Quimis, Diadema, SP, Brasil), submetidos a cinco minutos de centrifugação a $11.089 \mathrm{~g}$ (Vieira et al., 2008). Para a avaliação dos parâmetros sanguíneos pelo método automático, utilizou-se o contador hematológico automático modelo BC 2800 VET (Shenzhen Mindray Bio-Medical Electronics Co. Ltd, Shenzhen, Guangdong, China), com configuração para a espécie felina.
Para a análise estatística, avaliou-se o viés das diferenças entre as técnicas e a associação entre elas utilizando-se o teste $\mathrm{t}$ para dados pareados e a correlação utilizando-se o coeficiente de correlação de Pearson.

\section{RESULTADOS}

Os resultados dos testes comparativos entre os métodos manual e automatizado para contagem de eritrócitos, leucócitos, plaquetas e VG em jaguatiricas estão apresentados na Tab. 1.

Todos os parâmetros avaliados apresentaram boa correlação para as técnicas manual e automática. A pior correlação obtida foi entre a forma manual e a automática para plaquetas, evidenciada pela maior distância entre as setas (Fig. 1).

Tabela 1. Resultado das médias de contagens automatizada e manual de eritrócitos, volume globular, leucócitos e plaquetas de jaguatiricas (Leopardus pardalis) com seus valores de probabilidade $(\mathrm{P}>0,05)$ pelo cálculo do viés pelo teste t para dados pareados e estimativas de correlação de Pearson, com teste $t$ para correlação estatisticamente igual a zero

\begin{tabular}{|c|c|c|c|c|c|c|c|}
\hline Animais & Variável & Método & Média & Viés & P-value & Correl & P-value \\
\hline \multirow{8}{*}{$\begin{array}{c}\text { Jaguatirica } \\
n=8\end{array}$} & \multirow{2}{*}{ Eritrócitos } & Auto & 6.18 & & & & \\
\hline & & Manual & 6.24 & 0.06 & 0.720 & 0.84 & 0.009 \\
\hline & \multirow{2}{*}{ VG } & Auto & 35.30 & & & & \\
\hline & & Manual & 36.56 & 1.26 & 0.005 & 0.98 & 0.001 \\
\hline & \multirow{2}{*}{ Leucócitos } & Auto & 11.96 & & & & \\
\hline & & Manual & 11.94 & 0.02 & 0.910 & 0.99 & 0.001 \\
\hline & \multirow[t]{2}{*}{ Plaquetas } & Auto & 455.63 & & & 0.72 & 0.045 \\
\hline & & Manual & 377.42 & 78.21 & 0.092 & & \\
\hline
\end{tabular}

Legenda: auto = exame automatizado; correl = correlação; $\mathrm{VG}=$ volume globular.

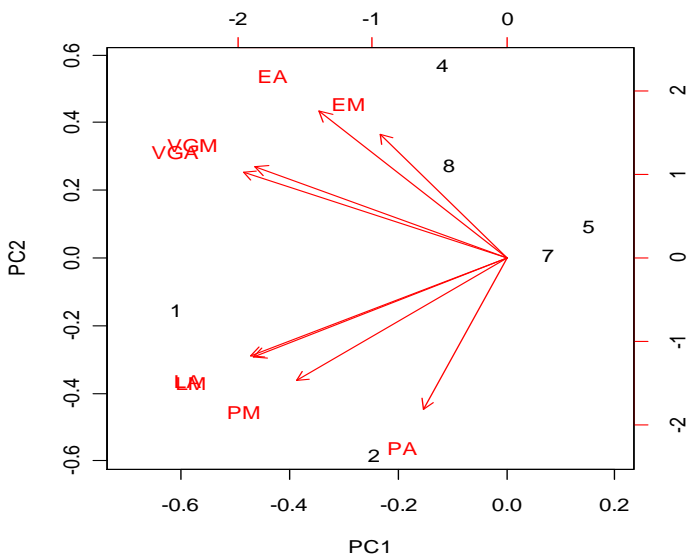

Figura 1. Análise gráfica das correlações entre variáveis hematimétricas (eritrócitos, volume globular, leucócitos e plaquetas) de jaguatiricas (Leopardus pardalis), por meio da técnica multivariada de componentes principais.
$\mathrm{EA}=$ eritrócitos automatizado; $\mathrm{EM}=$ eritrócitos manual; VGA = volume globular automatizado, VGM = volume globular manual; LA = leucócitos automatizado; LM = leucócitos manual; $\mathrm{PA}=$ plaquetas automatizado, $\mathrm{PM}=$ plaquetas manual.

Não houve diferença entre as técnicas manual e automática para o parâmetro eritrócitos, sendo, inclusive, o viés da diferença muito pequeno e a correlação boa (Fig. 2).

Para a variável VG, houve diferença significativa entre as técnicas manual e automatizada. No entanto, como as técnicas foram altamente correlacionadas e o viés foi constante (Fig. 3A), pôde-se empregar, portanto, o viés como um fator de correção quando se empregou a técnica automática. 


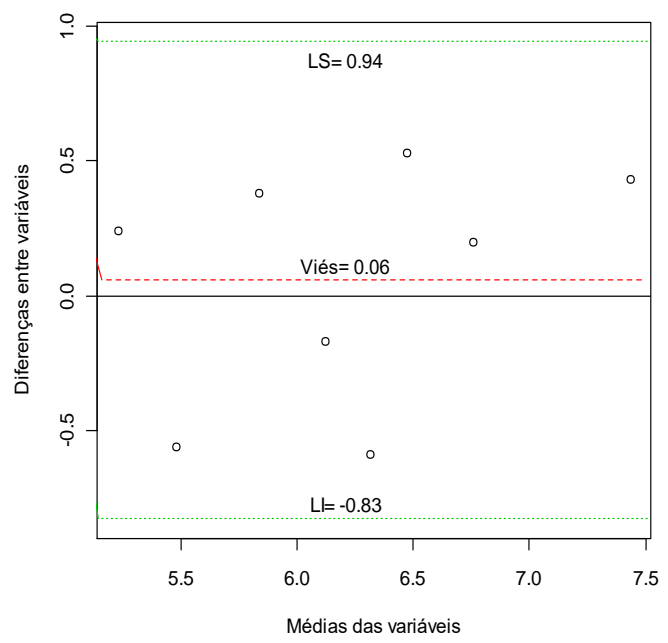

A

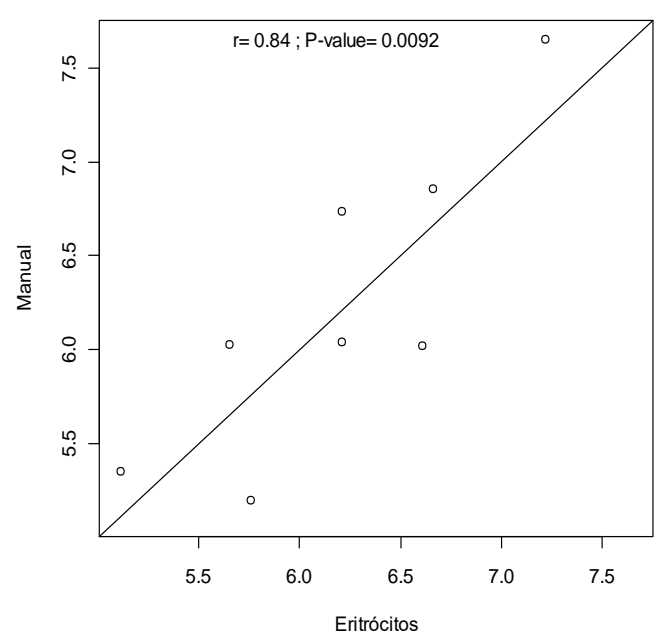

B

Figura 2. Representação da dispersão das médias obtidas para a variável eritrócito (A) de jaguatiricas (Leopardus pardalis). Representação da associação entre as técnicas manual e automática para a variável eritrócito, por meio do teste t para dados pareados (B).

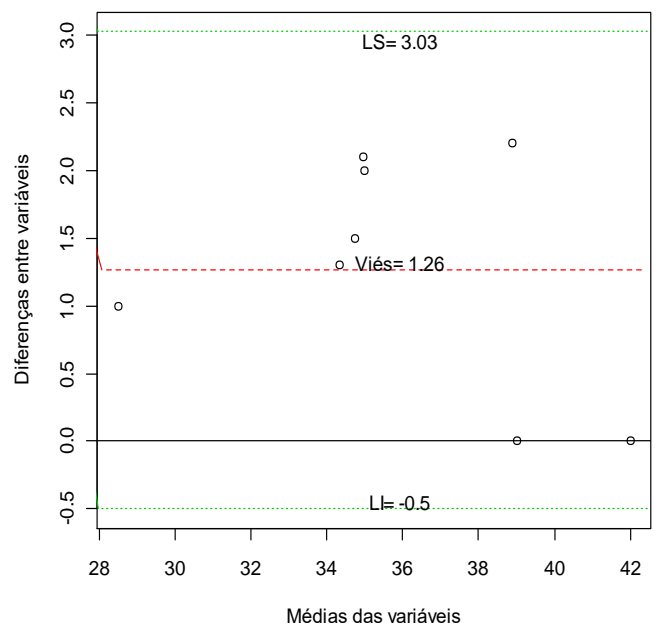

A

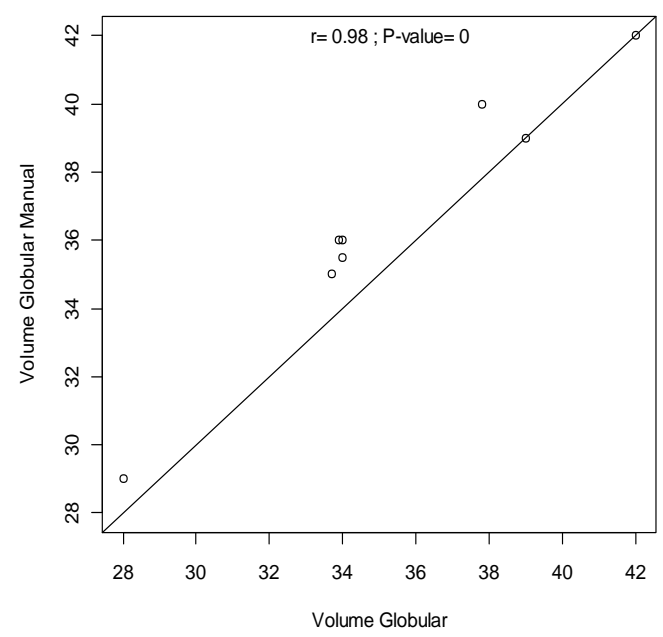

B

Figura 3. Representação da dispersão das médias obtidas para a variável volume globular (A) de jaguatiricas (Leopardus pardalis). Representação da associação entre as técnicas manual e automática para a variável volume globular por meio do teste t para dados pareados (B).

Em relação à variável leucócitos, as técnicas mostraram resultados muito semelhantes, sendo o viés da diferença muito próximo de zero (Fig. 4A). As técnicas foram altamente correlacionadas (Fig. 4B).
Para a variável plaquetas, no entanto, apesar de não haver diferença significativa a $5 \%$ de probabilidade, essa diferença existiria considerando-se $10 \%$ de probabilidade. Adicionalmente, as técnicas não foram bem correlacionadas (Fig. 5). 


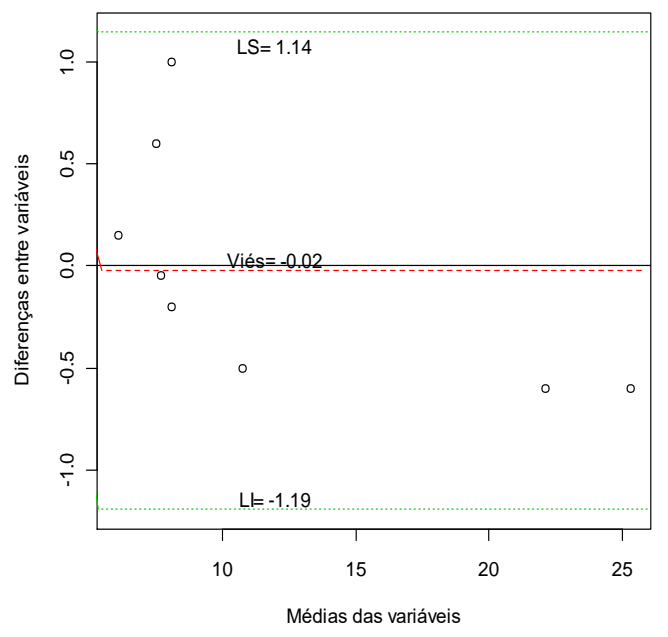

A

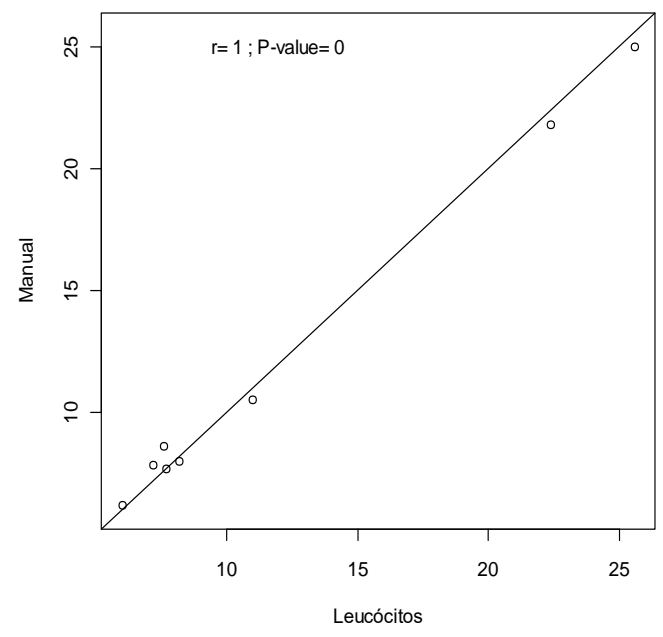

B

Figura 4. Representação da dispersão das médias obtidas para a variável leucócitos (A) de jaguatiricas (Leopardus pardalis). Representação da associação entre as técnicas manual e automática para a variável leucócitos por meio do teste $t$ para dados pareados (B).

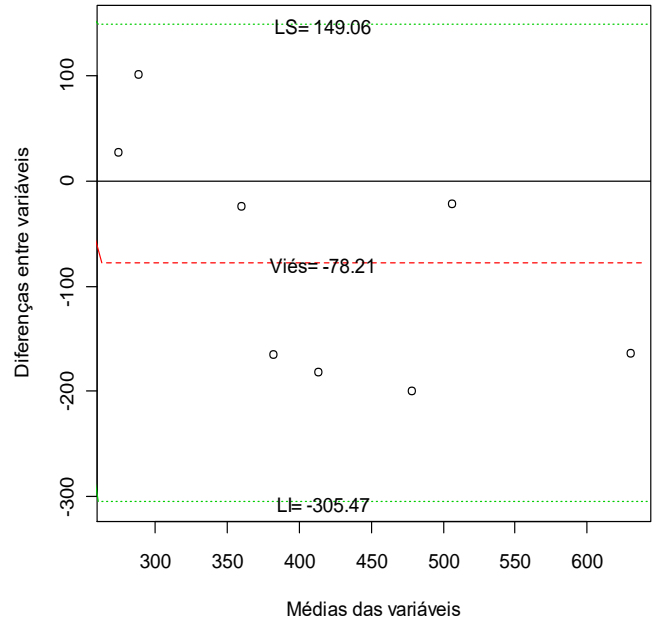

A

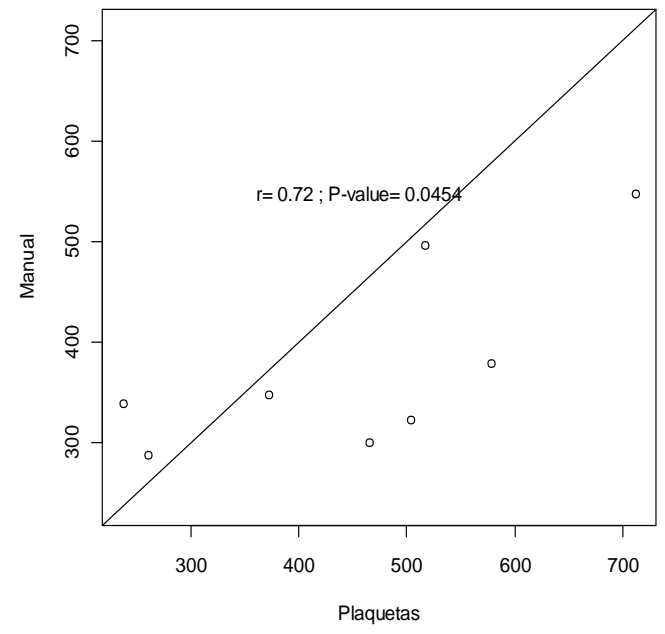

B

Figura 5. Representação da dispersão das médias obtidas para a variável plaquetas (A) de jaguatiricas (Leopardus pardalis). Representação da associação entre as técnicas manual e automática para a variável plaquetas por meio do teste t para dados pareados (B).

\section{DISCUSSÃO}

Os valores obtidos com ambas as técnicas estiveram no intervalo de referência de normalidade descrito para a espécie jaguatirica de acordo com Santos (1999) e mostraram-se altamente correlacionados, principalmente para os parâmetros leucócitos e VG. 
Como neste trabalho, Vieira et al. (2008) também descreveram alta correlação entre a técnica de micro-hematócrito por meio do aparelho BC - 2800 VET $^{\circledR}$ na determinação do VG para gatos domésticos. Contudo, para essa espécie, os valores de VG encontrados foram superiores quando utilizado $\mathrm{o}$ aparelho de automação, sendo os maiores valores obtidos com essa técnica atribuídos ao empilhamento característico dos eritrócitos (rouleaux) na espécie felina. Contudo, as jaguatiricas apresentaram valor médio superior na técnica manual. Para as jaguatiricas, apesar de as técnicas manuais e de automação terem sido altamente correlacionadas, houve diferença significativa entre elas; desse modo, quando o aparelho $\mathrm{BC}-2800 \mathrm{VET}^{\circledR}$ for utilizado na determinação do VG para essa espécie, deve-se fazer a correção de pelo menos $1,25 \%$ a mais no resultado obtido.

A contagem de plaquetas pelo aparelho BC 2800 VET $^{\circledR}$ não apresentou diferenças em relação ao método manual. Entretanto, o viés da diferença foi grande e a correlação entre as técnicas foi baixa; assim, é preferível realizar a contagem manual de plaquetas para jaguatiricas. Também é importante salientar que a análise morfológica por meio dos esfregaços não pode ser descartada, pois é a única que permite avaliar alterações morfológicas nas plaquetas (Schweirgert et al., 2010).

No presente estudo, a técnica automática mostrou alta correlação e adequação na obtenção de resultados de valores de eritrócitos e leucócitos, porém, para a obtenção de maior sensibilidade diagnóstica, é indicado o estabelecimento de valores hematológicos de referência que considere a metodologia adotada no laboratório.

Diante do exposto, conclui-se que o aparelho de automação hematológica configurado para gatos domésticos pode ser utilizado para a determinação do número de eritrócitos e de leucócitos para jaguatiricas. O aparelho pode ser ainda utilizado para a obtenção do VG, desde que se faça a correção pelo viés. Em relação às plaquetas, aconselha-se que se faça a contagem manual pelo método de Fônio.

\section{REFERÊNCIAS}

ABREU, K.C.; MOROS-RIOS, R.F.; SILVAPEREIRA, J.E. et al. Feeding habitats of ocelot (Leopardus pardalis) in Southern Brazil. Mamm. Biol., v.73, p.407-411, 2008.

BECKER, M.; MORITZ, A.; GIGER, U. Comparative clinical study of canine and feline total blood cell count results with seven in-clinic and two commercial laboratory analyzers. Vet. Clin. Pathol., v.37, p.373-384, 2008.

BRAHIMI, M.; OSMANI, S.; ARABI, A. et al. The estimation of platelet count from a blood smear on the basis of the red cell: Platelet ratio. Turk. J. Hematol., v.26, p.21-24, 2009.

BRASIL. Ministério do Meio Ambiente. Instituto Brasileiro do Meio Ambiente e dos Recursos Naturais Renováveis. Lista da fauna brasileira ameaçada de extinção, 2003. Disponível

em: <http://www.meioambiente.es.gov.br/download/ NovaListaFaunaAmeacaMMA2003.pdf >.

Acessado em: 17 abr. 2015.

CONVENTION on international trade in endangered species of wild fauna and flora, appendices I, II and III, 2013. Available in: <http://www.cites.org/eng/app/appendices.shtm> . Accessed in: 10 Set. 2015.

GONZÁLEZ, F.H.D.; CARVALHO, V.; MOLLER, V.A.; DUARTE, F.R. Perfil bioquímco sanguíneo de cães e gatos na cidade de Porto Alegre, Rio Grande de Sul, Brasil. Acta Sci. Vet., v.29, p.1-6, 2001.

NOWAK, R.M. (Ed.). Walker's mammals of the world. 6.ed. Baltimore: Johns Hopkins University Press, 1999. 1936p.

PAZ, R.C.R.; ADANIA, C.H.; BARNABE, V.H.; BARNABE, R.C. Detecção de estro em jaguatirica (Leopardus pardalis) utilizando citologia vaginal. Braz. J. Vet. Anim. Sci., v.62, p.1409-1414, 2010.

SANTOS, L.C. (Ed.). Laboratório ambiental. Cascavel: Edunioeste, 1999. 341p.

SCHWEIRGERT, A.; REZENDE, F.H.; FANTONI, D.T.; MOROZ, L.R. Avaliação da contagem plaquetária pelo contador automático QBC Vet Autoread® comparado com estimativa em esfregaço sanguíneo e contagem em hemocitômetro. Semin. Ciênc. Agrár., v.31, p.1001-1008, 2010. 
SILVA, R.C.; COSTA, G.M.J.; ANDRADE, L.M.; FRANÇA, L.R. Testis stereology, seminiferous epithelium cicle lenght, and daily sperm production in the ocelot (Leopardus pardalis). Theriogenology, v.73, p.157-167, 2010.

ULLMANN, L.S.; SILVA, R.C.; MORAES, W. et al. Serological survey of Toxoplasma gondii in captive Neotropical felids from Southern Brazil. Vet. Pathol., v.172, p.144-146, 2010.
VIEIRA, R.F.C.; VIOL, M.A.; BARBOSA, T.S. et al. Uso da impedância na determinação do volume globular das espécies felina, equina e bovina. Arch. Vet. Sci., v.13, p.167-171, 2008.

WEISER, G. Laboratory technology for veterinary medicine. In: THRALL, M.A. (Ed.). Veterinary hematology and clinical chemistry. 2.ed. Philadelphia: Lippincott Williams \& Wilkins, 2012. p.3-36. 